\title{
ErbB2 and ErbB3 regulate recovery from dextran sulfate sodium-induced colitis by promoting mouse colon epithelial cell survival
}

\author{
Yongqin Zhang ${ }^{1}$, Philip E Dubé ${ }^{1, *}$, M Kay Washington ${ }^{2}$, Fang Yan ${ }^{1}$ and D Brent Polk ${ }^{1,3, *}$
}

ErbB2 and ErbB3 receptor tyrosine kinases are key regulators of proliferation, migration, differentiation and cell survival; however, their roles in gastrointestinal biology remain poorly defined. We hypothesized that ErbB2 and ErbB3 promote colon epithelial cell survival in the context of the wound-healing response following colitis. In this study, mice bearing intestinal epithelial-specific deletion of ErbB2 or ErbB3 were treated with dextran sulfate sodium (DSS). Colon sections were examined for injury, cytokine expression, epithelial cell proliferation and apoptosis. Deletion of epithelial ErbB2 did not affect the extent of intestinal injury in response to DSS, whereas deletion of ErbB3 slightly increased injury. However, the roles of both receptors were more apparent during recovery from DSS colitis, in which ErbB2 or ErbB3 epithelial deletion resulted in greater inflammation and crypt damage during the early reparative period. Moreover, loss of ErbB3 prevented normal epithelial regeneration in the long term, with damage persisting for at least 6 weeks following a single round of DSS. Delayed recovery in mice with epithelial deletion of ErbB2 or ErbB3 was associated with increased colonic expression of tumor necrosis factor alpha and increased epithelial apoptosis. Furthermore, epithelial ErbB3 deletion increased apoptosis at baseline and during DSS injury. Additionally, epithelial cell hyperproliferation during recovery was exacerbated by deletion of either ErbB2 or ErbB3. These results suggest that ErbB2 and ErbB3 have important cytoprotective and reparative roles in the colonic epithelium following injury, by promoting colon epithelial cell survival.

Laboratory Investigation (2012) 92, 437-450; doi:10.1038/labinvest.2011.192; published online 12 December 2011

KEYWORDS: apoptosis; colitis; ErbB2; ErbB3; proliferation; TNF- $\alpha$

Growth factors have significant roles in maintaining epithelial integrity through the regulation of intestinal epithelial cell migration, proliferation and cell survival. ${ }^{1,2}$ Disruption of intestinal epithelial integrity contributes to the pathogenesis of several gastrointestinal disorders, including inflammatory bowel disease. The ErbB family of receptor tyrosine kinases, consisting of ErbB1 (EGFR), ErbB2 (Her2), ErbB3 (Her3) and ErbB4 (Her4), can be activated by direct interaction with ligands or by forming heterodimers with other ErbBs, leading to increased kinase activity and downstream signal transduction. The ErbB family members are potential therapeutic targets as evidenced by the protective effects of EGF in experimental colitis and in clinical trials with ulcerative colitis. ${ }^{3,4}$
However, the direct influence of individual ErbBs on intestinal injury and repair in vivo is relatively not well defined.

ErbB2 has been extensively studied in many types of cancers $;{ }^{5}$ however, determination of its role in intestinal development and epithelial response to injury and inflammation has been hampered by the fact that ErbB2 deletion is embryonic lethal due to both cardiac and neural defects. ${ }^{6}$ Although no ligands have been identified for ErbB2, its activation can be induced by heterodimerization with ligandoccupied EGFR, ErbB3 or ErbB4. ${ }^{7}$ ErbB2 has been implicated in mediating myoblast cell survival and in inhibiting cancer cell apoptosis. ${ }^{8,9}$ In addition, our group has shown that ErbB2 is transactivated by tumor necrosis factor alpha (TNF- $\alpha$ ),

\footnotetext{
${ }^{1}$ Department of Pediatrics, Division of Gastroenterology, Hepatology and Nutrition, Vanderbilt University School of Medicine, Nashville, TN, USA; ${ }^{2}$ Department of Pathology, Vanderbilt University School of Medicine, Nashville, TN, USA and ${ }^{3}$ Department of Cell and Developmental Biology, Vanderbilt University School of Medicine, Nashville, TN, USA

Correspondence: Dr DB Polk, MD, Children's Hospital Los Angeles, 4650 Sunset Boulevard MS\#126, Los Angeles, CA 90027, USA.

E-mail: dbpolk@chla.usc.edu

${ }^{*}$ Current address: Department of Pediatrics, University of Southern California and The Saban Research Institute of Children's Hospital Los Angeles, Los Angeles, CA, USA.
}

Received 4 May 2011; revised 12 October 2011; accepted 27 October 2011 
which in turn protects intestinal epithelial cells from TNF- $\alpha$ induced apoptosis. ${ }^{10}$

Interestingly, increased ErbB3 expression has been found in many tumors that overexpress ErbB2. ${ }^{11,12}$ In contrast to ErbB2, ErbB3 binds numerous ligands including neuregulin; however, ErbB3 lacks intrinsic kinase activity, and downstream signal transduction relies on heterodimerization with other ErbBs. For example, the ErbB2-ErbB3 dimer is crucial for ErbB2-mediated proliferation in ErbB2-overexpressing tumors. ${ }^{13}$ ErbB3 signaling likely has an important role in cell survival, given that there are six putative PI3 kinase-binding sites within its C-terminal domain. ${ }^{14}$ Indeed, ErbB3 silencing by siRNA promotes apoptosis in lung adenocarcinoma cells. ${ }^{15}$ However, delineation of the physiological role of ErbB3 has been difficult, as, like ErbB2, ErbB3 deletion also causes embryonic lethal cardiac and neural defects. ${ }^{16}$ ErbB3 deletion in the intestinal epithelium sensitizes the colonic epithelium to dextran sulfate sodium (DSS)-induced colitis; ${ }^{17}$ however, the mechanism by which ErbB3 protects from injury and the effect of ErbB3 on intestinal epithelial recovery following injury are not known.

Numerous studies have implicated ErbB ligands and EGFR in the protection against DSS-induced colitis. ${ }^{18-20}$ As EGFR and ErbB2 promote intestinal epithelial cell survival in vitro and in vivo in the presence of TNF- $\alpha$, we hypothesized that ErbB2 and ErbB3 protect the intestinal epithelium during injury and inflammation in vivo. DSS causes a chemically induced colitis, ${ }^{21,22}$ with direct cytotoxic insult to the colon epithelium. This results in a well-characterized pattern of increased apoptosis, subsequent disruption of crypt structure, followed by severe inflammation ${ }^{22,23}$ and extensive proliferation to restore the epithelial barrier. ${ }^{23}$ Using this model, we studied the role of ErbB2 and ErbB3 in injury/ repair responses, using mice with intestinal epithelial cellspecific ErbB2 or ErbB3 deletion. Our data show that intestinal epithelium-specific ErbB3 knockout mice develop worse colitis than controls and that ErbB2 and ErbB3 both have important roles in epithelial recovery following injury. Deletion of ErbB2 or ErbB3 increases colonic TNF- $\alpha$ production, epithelial apoptosis, and worsens colitis. In addition, deletion of ErbB3 resulted in histological evidence of sustained colitis for at least 6 weeks, following a single DSS insult. These findings provide important insights into the specific roles of ErbB2 and ErbB3 in vivo in the regulation of crypt survival and epithelial recovery following colonic injury.

\section{MATERIALS AND METHODS}

\section{Mice and DSS Treatment}

All animal procedures were approved by the Vanderbilt Institutional Animal Care and Use Committee. ErbB2 $2^{\text {flox/flox }}$ (FVB background) or ErbB $3^{\text {flox/flox }}$ (129 background) mice were crossed with villin-Cre ${ }^{24}$ (C57BL/6) mice to generate constitutive intestinal epithelium-specific ErbB2 knockout $\left(\right.$ ErbB2 $\left.\mathrm{KO}^{\mathrm{IEC}}\right)$ or ErbB3 knockout mice $\left(\right.$ ErbB3 $\left.\mathrm{KO}^{\mathrm{IEC}}\right){ }^{8,17}$
Littermate $\mathrm{ErbB}^{\text {flox/flox }}$ (wild type) or $\mathrm{ErbB}^{\text {flox/flox }}$ (wild type) mice were used as control mice. $\mathrm{ErbB} 3^{\text {flox/flox }}$ mice were also crossed with villin-Cre ERT2 ${ }^{24}$ (C57BL/6) mice to generate tamoxifen-inducible ErbB $3^{\text {flox/flox}} /$ Cre ERT2 mice. Intestinal epithelium-specific ErbB3 knockout mice (ErbB3 $\mathrm{KO}^{\mathrm{IEI}}$ ) were obtained by giving tamoxifen to 6-8-week-old ErbB3 ${ }^{\text {flox/flox}} /$ Cre ERT2 mice $(1 \mathrm{mg} /$ mouse, i.p., Sigma Chemical, St Louis, MO, USA) for 5 days, as reported. ${ }^{24}$ $\mathrm{ErbB}^{\text {flox/flox}} /$ Cre ERT2 mice receiving vehicle only (sunflower oil, Sigma) were used as controls (wild type) for inducible ErbB3 deletion. Experiments began 4 weeks following tamoxifen to allow for efficient Cre-mediated recombination of the floxed ErbB3 allele.

To induce colitis, mice received DSS $(36-50 \mathrm{kDa}$; MP Biomedicals, Solon, OH, USA) dissolved in water $(3 \% \mathrm{w} / \mathrm{v})$ for 4-8 days, as indicated. Control groups received normal drinking water without DSS. Mice were either killed immediately after DSS treatment or allowed to recover for the indicated times on normal drinking water. All groups contained balanced numbers of age-matched male and female mice.

\section{Epithelium Isolation and Western Blot Analysis}

Epithelial cell isolation and western blot analysis was performed as previously described. ${ }^{25}$ Colons were cut into 4-5 $\mathrm{mm}$ pieces and incubated in Cell Recovery Solution (BD Biosciences, San Jose, CA, USA) at $4{ }^{\circ} \mathrm{C}$ overnight, followed by manual shaking to release the epithelial fraction; the stromal fraction consisted of the remaining tissue. Western blotting against E-cadherin was used to determine the purity of epithelial and stromal fractions. Tissue lysates were made with RIPA buffer ${ }^{26}$ (1\% Triton X-100, $1 \mathrm{mM}$ EDTA, $10 \mathrm{mM}$ Tris, $\mathrm{pH} 7.4,150 \mathrm{mM} \mathrm{NaCl}, 0.1 \%$ SDS, $0.2 \%$ sodium deoxycholate) with protease and phosphatase inhibitors (Sigma Chemical). Cell lysates were subjected to SDS-PAGE and transferred onto nitrocellulose membranes. Membranes were blocked with milk, incubated with primary antibodies at $4{ }^{\circ} \mathrm{C}$ overnight, and then incubated with horseradish peroxidaseconjugated secondary antibodies. Membranes were developed using Western Lighting (Perkin Elmer, Waltham, MA, USA).

\section{Histological Scoring}

The extent of injury and inflammation was scored by a gastrointestinal pathologist blinded to genotype and treatment. After the mice were killed, colons were removed, opened longitudinally, rolled from the distal to proximal end and fixed in 10\% neutral-buffered formalin; paraffin-embedded sections $(5 \mu \mathrm{m})$ were then prepared and H\&E stained as previously reported. ${ }^{25}$ Histological scores were evaluated using a protocol described by Dieleman et al, ${ }^{27}$ which quantifies colitis according to the following five categories in which each category has a score range from 0 to 3 : the amount of inflammation, depth of inflammation, percentage of the crypts involved by inflammation, crypt damage, and 
the percentage of crypts involved by crypt damage. The total injury and inflammation score is the sum of the individual scores assigned to each category according to severity and extent of colitis as we have previously reported. ${ }^{25}$

\section{Real-Time PCR Analysis}

Total RNA was isolated from whole colon tissue using a Qiagen RNA isolation kit (Qiagen, Valencia, CA, USA) following the manufacturer's instructions, including DNase digestion. An RNA sample of $1 \mu \mathrm{g}$ was then reverse transcribed using the high-capacity cDNA reverse transcription kit (Applied Biosystem, Foster City, CA, USA). Quantitative real-time PCR was performed on an iCycler iQ5 system (Bio-Rad, Hercules, CA, USA) using SYBR green PCR Master Mix (Bio-Rad) for TNF- $\alpha$, or on an ABI7000 system (Applied Biosystems) using a primer and probe set (Assay ID: Mm99999071_m1; Applied Biosystems) for IFN- $\gamma$. Actin expression was used as internal reference in all PCR experiments. The PCR primer sequences used were as follows: TNF- $\alpha, 5^{\prime}$-CTGTGAAGGGAATGGCTGTT- $3^{\prime}$ and $5^{\prime}$-GGTCA CTGTCCCAGCATCTT- $3^{\prime}$; actin, 5'-GAAGCATTTGCGGTG GACGAT- $3^{\prime}$ and 5'-CCAGGTCATCACCATTGGCAA- $3^{\prime}$.

\section{Apoptosis}

Apoptotic cells were detected within tissue samples using terminal deoxynucleotidyl transferase-mediated dNTP nickend labeling (TUNEL) as previously reported. ${ }^{28}$ Briefly, $5 \mu \mathrm{m}$ paraffin-embedded colon sections were deparaffinized, rehydrated and then pretreated with proteinase $\mathrm{K}(20 \mu \mathrm{g} / \mathrm{ml})$ for $15 \mathrm{~min}$ at room temperature, followed by incubation with $3 \% \mathrm{H}_{2} \mathrm{O}_{2}$ for $5 \mathrm{~min}$ to quench endogenous peroxidase. Apoptotic cells were labeled using a TUNEL assay kit according to the manufacturer's instructions (ApopTag, number S7100; Millipore) and sections were counterstained with hematoxylin. TUNEL-positive cells were counted in a blinded fashion and expressed as the number of apoptotic cells per 100 colonic crypts as we have previously reported. ${ }^{29}$

\section{Immunohistochemistry}

Slides were stained using previously described approaches. ${ }^{25}$ Paraffin-embedded colon sections were deparaffinized, rehydrated and subjected to antigen retrieval by boiling in either citrate buffer (Vector Labs) or target solution (DAKO). Sections were then blocked with 10\% goat serum (Zymed, Carlsbad, CA, USA) and stained with rabbit anti-ErbB2 (Abcam, Cambridge, MA, USA) or rat anti-Ki67 antibody (DAKO, for determining epithelial cell proliferation) as previously reported. ${ }^{25}$ Slides were incubated with horseradish peroxidase-conjugated goat anti-rabbit or anti-rat antibodies and developed with DAB substrate (Sigma Chemical). Ki67-positive staining epithelial cells in 30 crypts from distal colon for each mouse were counted in a blinded fashion and expressed as the number of proliferating cells per crypt.

For colonic expression of ErbB3, $5 \mu \mathrm{m}$ frozen colon sections were fixed in methanol $\left(5 \mathrm{~min}\right.$ at $\left.-20^{\circ} \mathrm{C}\right)$ and blocked in $1 \% \mathrm{BSA} / 0.2 \%$ non-fat, dry milk in PBS for $20 \mathrm{~min}$ at room temperature. Sections were stained with antibody against ErbB3 (Santa Cruz Biotechnology, Santa Cruz, CA, USA) at $4{ }^{\circ} \mathrm{C}$ overnight and then with rhodamine-conjugated antirabbit antibody at room temperature for $30 \mathrm{~min}$. Slides were mounted with aqueous solution containing DAPI to counterstain nuclei. ErbB3 expression was visualized with standard fluorescence microscopy.

\section{Statistics}

Statistical significance for injury scores, mRNA transcript expression and proliferative and apoptotic indices were determined using the non-parametric Mann-Whitney test. Body weights were analyzed using unpaired Student's $t$-tests. Twosided $P$-values are reported for all tests and $P$-values $<0.05$ were considered significant. Statistical analyses were performed using GraphPad Prism software (GraphPad Software, San Diego, CA, USA).

\section{RESULTS \\ Deletion of Colonic Epithelial ErbB2 Delays Colon Epithelial Recovery Following DSS-Induced Colitis}

ErbB2 mediates cell survival in addition to its more established roles in regulating cell migration, proliferation and differentiation. ${ }^{8,10,15}$ As global deletion of ErbB2 leads to embryonic lethality, ${ }^{6,16}$ we used intestinal epithelium-specific ErbB2 (ErbB2 $\mathrm{KO}^{\mathrm{IEC}}$ ) knockout mice to test the hypothesis that ErbB2 protects the intestinal epithelium from injury and promotes epithelial recovery following injury in experimental colitis. ErbB2 $\mathrm{KO}^{\mathrm{IEC}}$ mice were generated by crossing ErbB2 $2^{\text {flox/flox }}$ (wild type) mice with mice expressing a constitutively active Cre recombinase driven by the villin promoter. Intestinal epithelium-specific deletion of ErbB2 was confirmed by western blot analysis of isolated epithelial cells and by immunohistochemistry (Figure 1a); ErbB2 protein was efficiently deleted in the colonic epithelium, but not in the stroma of ErbB2 $\mathrm{KO}^{\mathrm{IEC}}$ mice. There were no changes in the expression of EGFR or ErbB3 in the ErbB2 $\mathrm{KO}^{\mathrm{IEC}}$ colon epithelium or stroma (data not shown).

In contrast to global ErbB2-knockout mice, ErbB2 $\mathrm{KO}^{\mathrm{IEC}}$ mice survived normally and exhibited no obvious phenotypic changes. Furthermore, these mice showed normal architecture of the epithelium in the small intestine (data not shown) and colon (Figure 2a). ErbB2 $\mathrm{KO}^{\mathrm{IEC}}$ mice also displayed no basal defects in epithelial cell proliferation or migration (data not shown).

Administration of DSS induces superficial mucosal erosions, mostly through direct cytotoxic damage to the colonic epithelium, leading to mucosal inflammation, ${ }^{21,22,27}$ and has been widely used to delineate the requirement of specific gene products and/or signaling pathways in response to tissue damage and inflammation. ${ }^{25,30}$ Therefore, we used this model to dissect the role of epithelial ErbB2 in intestinal injury and subsequent repair. ErbB2 $\mathrm{KO}^{\mathrm{IEC}}$ mice received either water alone or 3\% DSS for 4 days to induce colitis. 

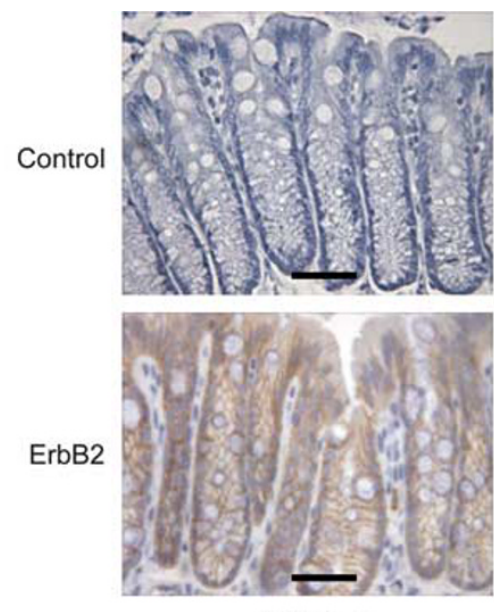

Wild-type
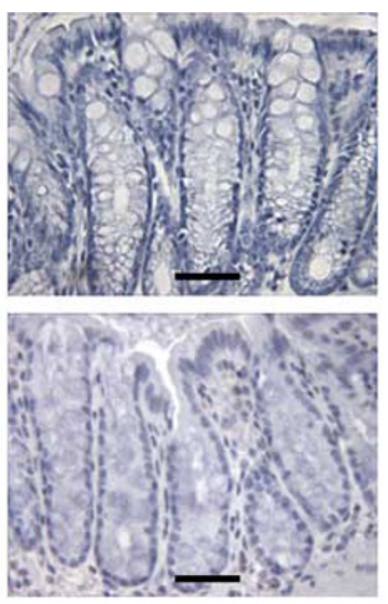

ErbB2 KO ${ }^{\mathrm{IEC}}$

b
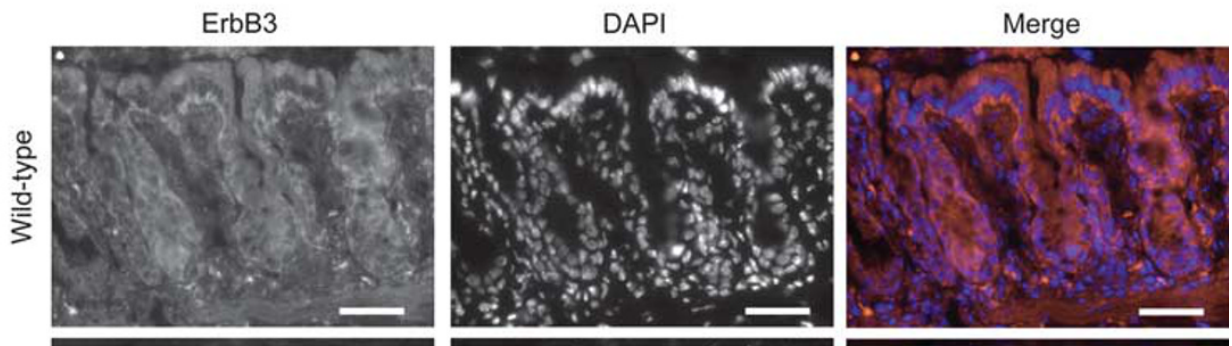

IB:Actin
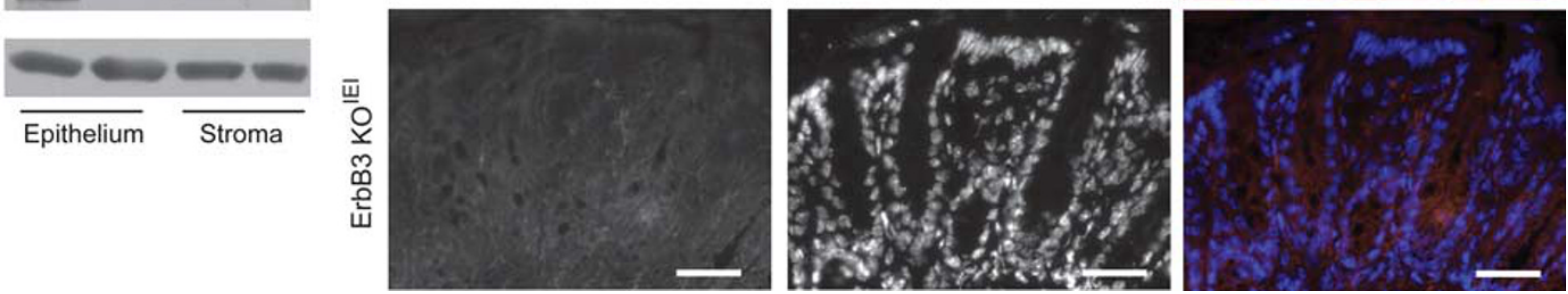

Figure 1 Deletion of colon epithelial ErbB2 or ErbB3 expression in ErbB2 $\mathrm{KO}^{\mathrm{IEC}}$ and ErbB3 $\mathrm{KO}^{\mathrm{IEI}}$ mice. Epithelial and stromal fractions were isolated from colons of the indicated mice. (a and $\mathbf{b})$ Western blot and immunohistochemical analysis with antibodies against ErbB2 (a) or ErbB3 (b). Omission of primary antibody was used as a control for immunohistochemistry. Actin expression was used as loading control. Brown indicates ErbB2 staining. Red indicates ErbB3 staining, blue indicates 4',6-diamidino-2-phenylindole (DAPI) staining. Scale bars, $50 \mu \mathrm{m}$. These results are representative of independent analyses of at least three different mice in each group.

After DSS treatment, wild-type and ErbB2 $\mathrm{KO}^{\mathrm{IEC}}$ mice showed a similar degree of colonic injury and inflammation (Figure 2a and c). During this 4-day DSS treatment, neither ErbB2-deleted mice nor their wild-type controls exhibited colitis-induced weight loss.

To assess whether loss of ErbB2 alters the response to a more severe injury, we then extended the length of DSS treatment. ErbB2 $\mathrm{KO}^{\mathrm{IEC}}$ mice treated with DSS for 7 days showed about $12 \%$ body weight loss (Figure 2e), after which treatment was discontinued to prevent extensive morbidity; in contrast, during this period, wild-type controls did not lose any body weight. After 7 days of DSS, wild-type and ErbB2-deleted mice each demonstrated extensive crypt damage and inflammation (Figure $2 \mathrm{a}$ and $\mathrm{c}$ ); although there was an apparent increase in the ErbB2 $\mathrm{KO}^{\mathrm{IEC}}$ injury scores, this difference did not reach statistical significance. However, as the ErbB2-knockout mice lost more body weight than wild-type controls during prolonged DSS treatment, this indicates that epithelial ErbB2 may contribute to protection from colitis that is not reflected in our injury score data.

To determine if epithelial ErbB2 has a role in epithelial re-establishment following injury, ErbB2 $\mathrm{KO}^{\mathrm{IEC}}$ mice were allowed to recover on normal drinking water for a 3-day period following 4 days of DSS treatment. Although no histological difference was observed between wild-type and ErbB2 $\mathrm{KO}^{\mathrm{IEC}}$ mice in a 4-day DSS-induced injury (Figure 2a and c), in this short-term recovery period, $\mathrm{ErbB} 2 \mathrm{KO}^{\mathrm{IEC}}$ mice exhibited exacerbated colitis with significantly increased injury and inflammation scores compared with wild-type controls (Figure $2 \mathrm{~b}$ and $\mathrm{d}$ ). Indeed, the extent of injury during this recovery period in ErbB2 $\mathrm{KO}^{\mathrm{IEC}}$ mice was greater and involved most of the mid and distal colon; in fact, some specimens displayed a complete denudation of the epithelium with full-thickness mucosal inflammation throughout the majority of the length of the colon. In contrast, although wild-type mice during this recovery period also displayed 

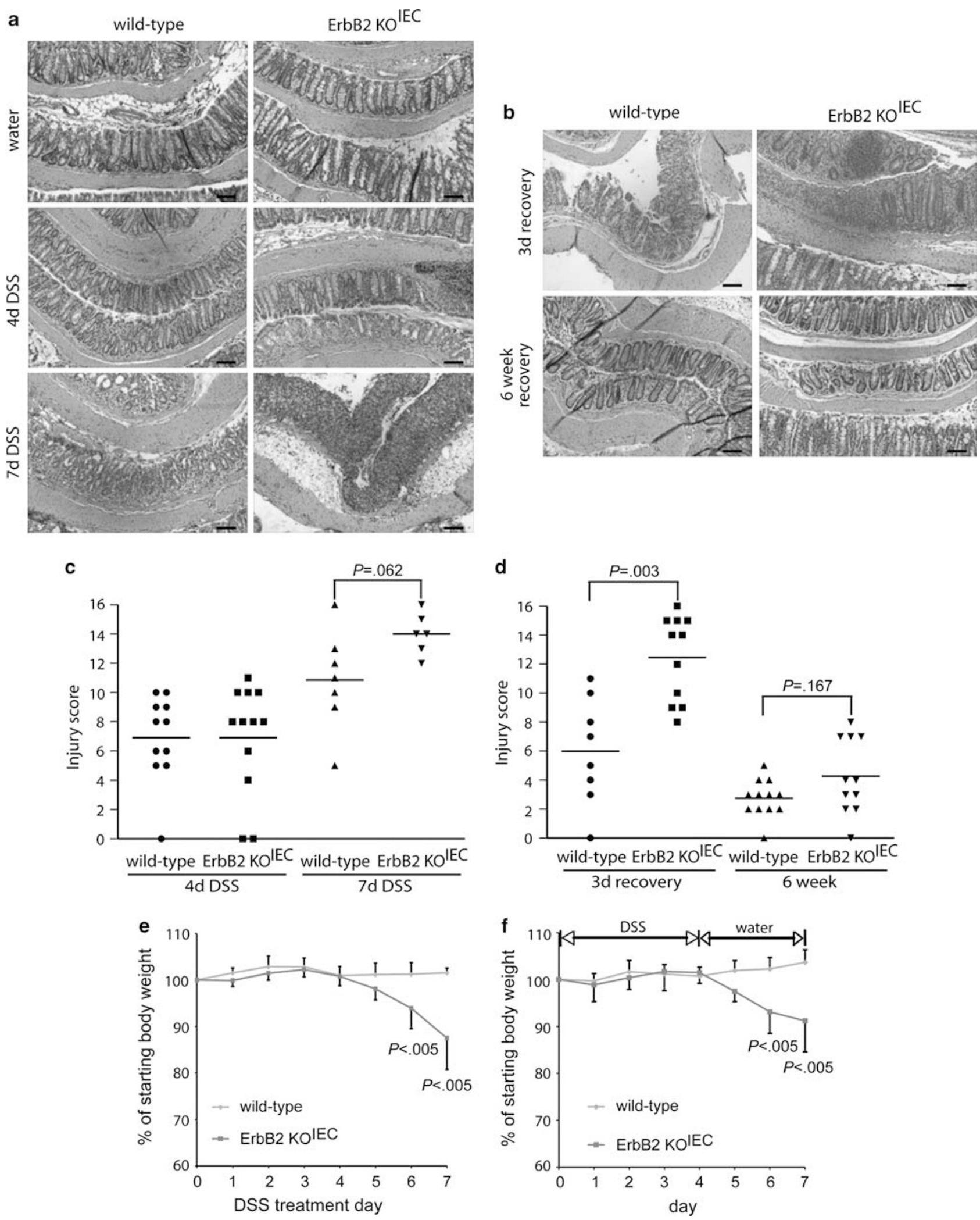

Figure 2 Epithelial ErbB2 is required for short-term recovery from dextran sulfate sodium (DSS)-induced colitis. ErbB2 $\mathrm{KO}^{\mathrm{IEC}}$ and wild-type controls were treated with 3\% DSS for 4 or 7 days $(\mathbf{a}, \mathbf{c}, \mathbf{e})$, or were treated with 3\% DSS for 4 days followed by a recovery period of 3 days or 6 weeks on normal water (b, d, f); $n=6-12$. (a, b) Representative hematoxylin and eosin (H\&E) sections of colons from the indicated mice. Scale bars, $100 \mu \mathrm{m}$. (c, $\mathbf{d})$ Colonic injury scores were quantified by a pathologist blinded to the treatment and group. Bars indicate mean value. (e) Body weight loss during DSS administration; values indicate mean \pm s.d. (f) Body weight loss during the 3-day recovery period following 4 days of DSS administration; values indicate mean \pm s.d. 
epithelial injury and mucosal inflammation, this occurred with a patchy distribution, sparing much of the mid colon. The percentage of the colon involved with crypt damage and inflammation was significantly higher in recovering ErbB2 $\mathrm{KO}^{\mathrm{IEC}}$ mice compared with control mice (Supplementary Figure 1). Interestingly, the body weight of ErbB2-knockout mice decreased after DSS withdrawal and was significantly lower during the second and third day of recovery than that of wild-type mice (Figure 2f). These results suggest that epithelial ErbB2 is crucial in the regenerative response of the epithelium following injury, with its absence leading to heightened inflammatory responses during recovery.

As DSS treatment induced a significant inflammatory response in recovering ErbB2-knockout mice, we determined whether epithelial ErbB2 deletion altered the phenotype of the immune response. However, flow cytometry analysis failed to detect any alterations in immune cell populations in the lamina propria of ErbB2 $\mathrm{KO}^{\mathrm{IEC}}$ mice when compared with wild-type controls (Supplementary Figure 2).

Furthermore, to rule out the possibility that Cre recombinase expression itself resulted in increased sensitivity to DSS, we treated mice carrying the villin-Cre recombinase alone with 3\% DSS for 4 days and then allowed the mice to recover for 3 days. No differences were observed in these mice compared with non-Cre-expressing control mice during the recovery phase as shown in Supplementary Figure 3. These data suggest that ErbB2 expression contributes to epithelial recovery in response to DSS-induced acute injury.

Given this exacerbated injury and inflammation following an initial DSS insult, we determined if this abnormal restitution in ErbB2 epithelial-null mice would lead to chronic changes. Thus, we extended the DSS recovery period to 6 weeks in ErbB2 $\mathrm{KO}^{\mathrm{IEC}}$ mice and wild-type controls, following a single insult of 4 days of DSS. Both wild-type and ErbB2 $\mathrm{KO}^{\mathrm{IEC}}$ mice showed complete weight recovery after DSS withdrawal for 6 weeks (not shown). Histological analysis indicated that the colons of ErbB2 $\mathrm{KO}^{\mathrm{IEC}}$ mice and controls had very mild colonic injury, with no differences observed between these two genotypes (Figure $2 \mathrm{~b}$ and $\mathrm{d}$ ). Thus, although the data suggest that epithelial ErbB2 was critical for short-term recovery from DSS injury, it appears to be dispensable during a longer recovery period.

\section{Deletion of ErbB3 in Colonic Epithelium Exacerbates DSS-Induced Injury and Impairs Recovery}

As global deletion of ErbB3 also leads to embryonic lethality, ${ }^{6,16}$ we used inducible intestinal epithelium-specific
ErbB3 (ErbB3 $\mathrm{KO}^{\mathrm{IEI}}$ ) knockout mice to determine the role that ErbB3 has in DSS-induced colitis. ErbB3 $\mathrm{KO}^{\mathrm{IEI}}$ mice were generated by crossing ErbB3 ${ }^{\text {flox/flox }}$ (wild type) mice with mice expressing a tamoxifen-inducible Cre recombinase under control of the villin promoter. Tamoxifen-induced intestinal epithelium-specific deletion of ErbB3 was confirmed as shown in Figure 1b; there were no changes in the expression of EGFR or ErbB2 (not shown). Deletion of epithelial ErbB3 did not cause defects in architecture of the epithelium in the small intestine (data not shown) or colon (Figure 3a), as well as basal epithelial cell proliferation or migration (data not shown).

For DSS-induced colitis, ErbB3 $\mathrm{KO}^{\mathrm{IEI}}$ mice received either water alone or 3\% DSS for 4 days to induce injury, 4 weeks following tamoxifen-induced ErbB3 deletion. After this DSS treatment, ErbB3 $\mathrm{KO}^{\mathrm{IEI}}$ mice showed slightly more histological damage compared with controls, although this did not reach statistical significance using conservative non-parametric methods (Figure 3a and c). However, ErbB3 $\mathrm{KO}^{\mathrm{IEI}}$ mice showed increased inflammatory infiltrate, greater depth of inflammation and a greater distribution of inflammation throughout the colon following acute injury versus wild-type controls. Neither genotype lost body weight during the 4-day DSS treatment (Figure 3e). To confirm that these results were specific to the role of epithelial ErbB3 in acute DSS injury in mice, we also studied constitutive deletion of epithelial ErbB3 $\left(\mathrm{ErbB} 3 \mathrm{KO}^{\mathrm{IEC}}\right)$. In agreement with results published by Lee et al, ${ }^{17} \mathrm{ErbB} 3 \mathrm{KO}^{\mathrm{IEC}}$ mice displayed greater histological injury following the 4day DSS treatment than wild-type controls (Supplementary Figure 4).

As with the ErbB2 $\mathrm{KO}^{\mathrm{IEC}}$ mice, we also tested the response of ErbB3 $\mathrm{KO}^{\mathrm{IEI}}$ mice to extended DSS treatment. ErbB3 $\mathrm{KO}^{\mathrm{IEI}}$ mice and wild-type controls were treated with DSS for 8 days; during this period, ErbB3 $\mathrm{KO}^{\mathrm{IEI}}$ mice lost $10 \%$ of their starting body weight, whereas wild-type controls maintained normal body weights (Figure 3e). Although both genotypes displayed extensive colonic injury, there was no difference in their injury scores following prolonged DSS treatment (Figure $3 a$ and $c$ ).

We then allowed ErbB3 $\mathrm{KO}^{\mathrm{IEI}}$ mice to recover on normal drinking water for a 3-day period following 4 days of DSS treatment to determine the role of ErbB3 in epithelial recovery after injury. In this short-term recovery period, significantly more severe damage was seen in ErbB3 $\mathrm{KO}^{\mathrm{IEI}}$ mice when compared with wild-type controls (Figure $3 \mathrm{~b}$ and di). As with the ErbB2 $\mathrm{KO}^{\mathrm{IEC}}$ mice, the extent of injury during this recovery period in the ErbB3 $\mathrm{KO}^{\mathrm{IEI}}$ mice was

Figure 3 Epithelial ErbB3 is required for short-term and long-term recovery from dextran sulfate sodium (DSS)-induced colitis. ErbB3 KO or ErbB3 KO ${ }^{\mathrm{IEC}}$ mice and their respective wild-type controls were treated with $3 \%$ DSS for 4 or 8 days (a, c, e), or were treated with $3 \%$ DSS for 4 days followed by a recovery period of 3 days or 6 weeks on normal water (b, d, f), as indicated; $n=7-13$. (a, b) Representative hematoxylin and eosin (H\&E) sections of colons from the indicated mice. Scale bars, $100 \mu \mathrm{m}$. (c, d) Colonic injury scores were quantified by a pathologist blinded to the treatment and group. Bars indicate mean value. (e) Body weight loss during DSS administration; values indicate mean \pm s.d. (f) Body weight loss during the 3-day recovery period following 4 days of DSS administration; values indicate mean \pm s.d. 


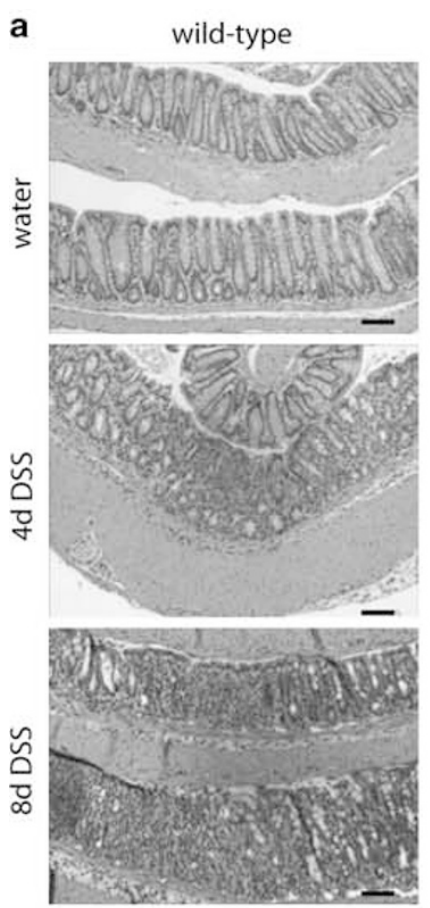

C

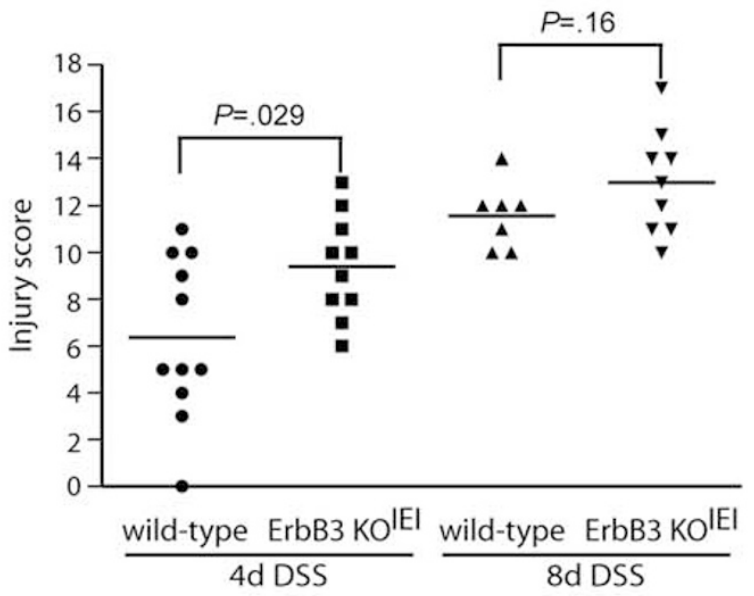

e

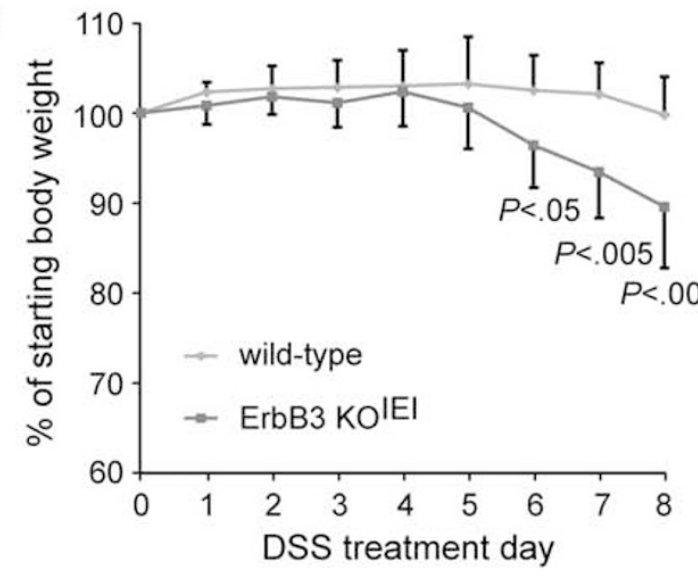

b
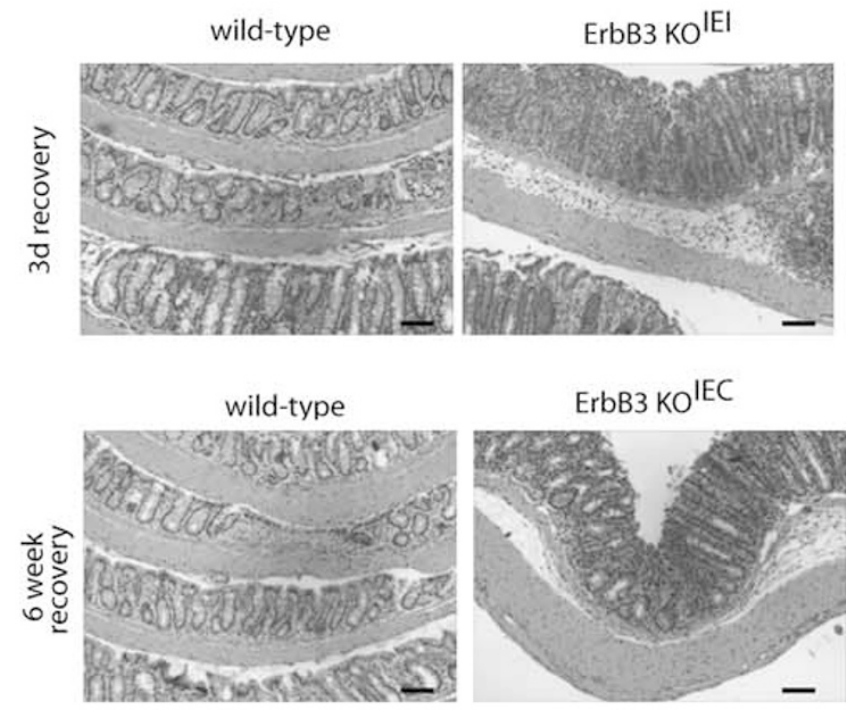

d
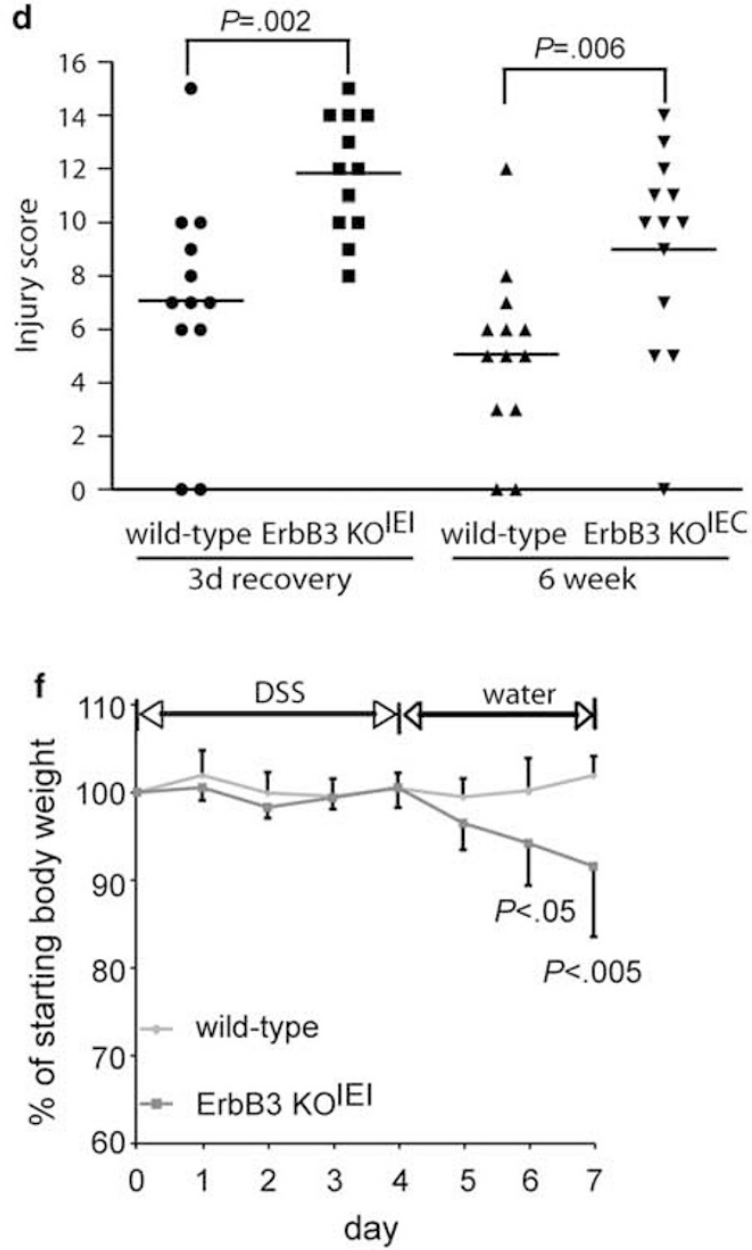
greater and involved most of the colon with epithelial denudation and full-thickness mucosal inflammation. In addition, ErbB3 $\mathrm{KO}^{\mathrm{IEI}}$ mice lost significantly more body weight than wild-type mice following DSS withdrawal (Figure 3f). These data provide evidence that epithelial ErbB3 is an important regulator of colonic epithelial repair following injury.

Given this exacerbated injury and inflammation in ErbB3 $\mathrm{KO}^{\mathrm{IEI}}$ mice during initial repair from a DSS insult, we tested whether ErbB3 regulates long-term recovery. Thus, we allowed wild-type and ErbB3 knockout mice to recover for 6 weeks after a single round of 4 days of DSS treatment. To study the long-term effect of ErbB3 deletion on recovery from DSS-induced colitis, we used ErbB3 $\mathrm{KO}^{\mathrm{IEC}}$ mice. After 6 weeks of recovery, ErbB3 $\mathrm{KO}^{\mathrm{IEC}}$ mice had significantly higher injury and inflammation scores when compared with wildtype littermate controls (Figure $3 \mathrm{~b}$ and $\mathrm{d}(\mathrm{ii})$ ). Initially, we had also used the inducible ErbB3 knockout (ErbB3 $\mathrm{KO}^{\mathrm{IEI}}$ ) for these studies. Although the tamoxifen-induced ErbB3 $\mathrm{KO}^{\mathrm{IEI}}$ mice initially exhibited significantly slower weight recovery following DSS withdrawal (Figure 3f), after 6 weeks, ErbB3 $\mathrm{KO}^{\mathrm{IEI}}$ mice only had a moderate, but similar degree of colitis to that of wild-type mice (Supplementary Figure 5). Given that inducible loss of ErbB3 caused such an extensive loss of the epithelium during the 3-day recovery period, this raised the possibility that there might be a strong selective pressure for rare ErbB3-expressing epithelial cells (ie, not recombined during prior tamoxifen treatment) during this 6-week recovery period. Indeed, western blot analysis indicated that epithelial ErbB3 expression was partially restored 6 weeks following DSS treatment in ErbB3 $\mathrm{KO}^{\mathrm{IEI}}$ mice (Supplementary Figure 5), whereas water-treated ErbB3 $\mathrm{KO}^{\mathrm{IEI}}$ mice did not show restoration of epithelial ErbB3 during the same time period. This suggests that selection for epithelial ErbB3-expressing cells may account for normal regeneration in these mice. Taken together, these data show that ErbB3 has a critical role in regeneration following DSS-induced injury.

\section{Increased Cytokine Expression in ErbB2 $\mathrm{KO}^{\mathrm{IEC}}$ and ErbB3 $\mathrm{KO}^{\mathrm{IEI}}$ During Recovery from DSS Injury}

DSS-induced colitis involves the release of proinflammatory cytokines such as TNF- $\alpha$ and IFN $\gamma$ by infiltrating immune cells in the lamina propria, which in turn further worsen subsequent injury. ${ }^{31}$ Therefore, we measured inflammatory cytokines in the colon during recovery in ErbB2 $\mathrm{KO}^{\mathrm{IEC}}$ and ErbB3 $\mathrm{KO}^{\mathrm{IEI}}$ mice. Although mRNA levels of IL- $1 \beta$ and IL-6 were not changed (data not shown), there were significantly higher mRNA levels of TNF- $\alpha$ and IFN- $\gamma$ in ErbB2 $\mathrm{KO}^{\mathrm{IEC}}$ mice following the 3-day recovery (Figure $4 \mathrm{a}$ and $\mathrm{b}$ ). Furthermore, in ErbB3 $\mathrm{KO}^{\mathrm{IEI}}$ mice, mRNA levels of TNF- $\alpha$ were also increased compared with controls following this 3-day recovery period (Figure 4c). Both ErbB2 $\mathrm{KO}^{\mathrm{IEC}}$ and ErbB3 $\mathrm{KO}^{\mathrm{IEI}}$ mice showed redistribution of the tight junctional
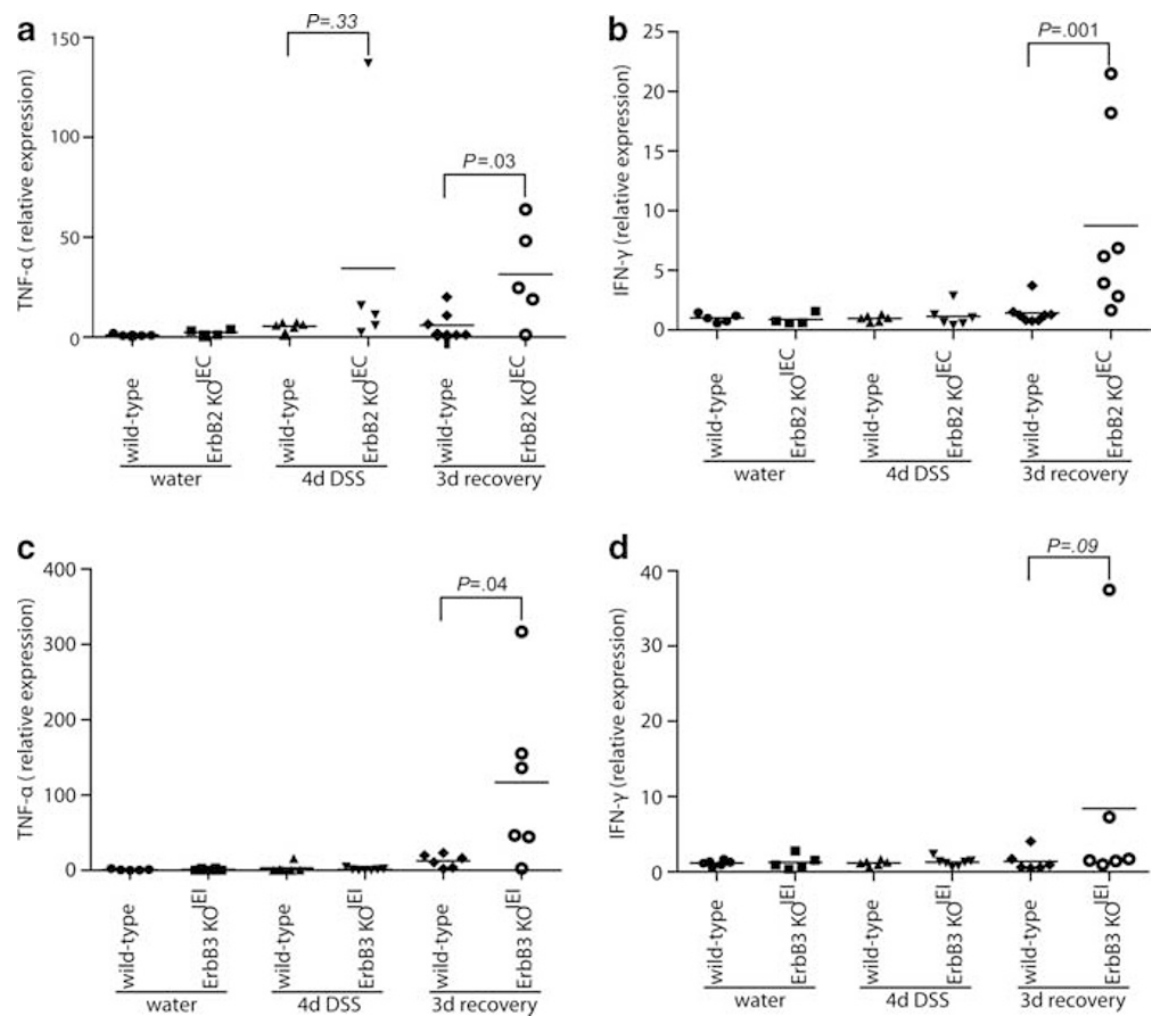

Figure 4 Colonic tumor necrosis factor alpha (TNF- $\alpha$ ) expression is increased in ErbB2 $\mathrm{KO}^{\mathrm{IEC}}$ and ErbB3 $\mathrm{KO} \mathrm{IEI}^{\mathrm{E}}$ mice during recovery from dextran sulfate sodium (DSS)-induced colitis. TNF- $\alpha(\mathbf{a}, \mathbf{c})$ and IFN- $\gamma(\mathbf{b}, \mathbf{d})$ mRNA transcript levels were measured by real-time reverse transcription (RT)-PCR from whole colon RNA of the indicated genotypes and treatment groups. Bars indicate mean expression of transcripts normalized for actin; $n=4-7$. 
protein, $\mathrm{ZO}-1$, in colonic sections during the recovery period from DSS colitis (Supplementary Figure 6). Taken together, these data are consistent with increased histological inflammation seen in recovering ErbB2 $\mathrm{KO}^{\mathrm{IEC}}$ and ErbB3 $\mathrm{KO}^{\mathrm{IEI}}$ mice.

\section{Colonic Epithelium of ErbB2 $\mathrm{KO}^{\mathrm{IEC}}$ and ErbB3 $\mathrm{KO}^{\mathrm{IEI}}$ Mice Retain Proliferative Capacity During Recovery from DSS Injury}

During recovery from acute injury, colon epithelial cells undergo extensive proliferation to re-establish the damaged epithelium. ${ }^{23}$ We examined crypt proliferation to determine whether epithelial-specific ErbB2- and ErbB3-null colons retained the capacity to repopulate the epithelium during the recovery phase following DSS-induced injury using immunohistochemistry for the proliferative marker Ki67. Deletion of ErbB2 or ErbB3 did not affect basal levels of proliferation in unchallenged mice (Figure 5). In contrast, following the 4-day DSS treatment, there was a significant decrease in the level of proliferation in ErbB3 $\mathrm{KO}^{\mathrm{IEI}}$ compared with the wild-type controls (Figure 5d). Despite this fact, this effect was relatively small and the ErbB3-null epithelium retained approximately $75 \%$ the proliferative capacity of wild-type controls. The effect on proliferation was most dramatic during the recovery period, in which loss of either ErbB2 or ErbB3 significantly increased, rather than decreased, the level of epithelial proliferation (144 and 145\% increase compared with wild-type controls, respectively). It is likely that this increased proliferation is an effect secondary to increased injury in these mice during recovery. Therefore, although the ErbB2- and ErbB3-null epithelium experiences more extensive damage during recovery from DSS-induced injury, these findings suggest that this is not likely due to an impairment in epithelial proliferation per se, and moreover, raises the possibility that ErbB2 and ErbB3 regulate epithelial regeneration by promoting cell survival.

\section{ErbB2 and ErbB3 are Differentially Required to Prevent Colon Epithelial Cell Apoptosis}

As apoptosis is a pathological feature of DSS colitis, ${ }^{22,23}$ we hypothesized that the increased severity of crypt damage and inflammation in ErbB2- and ErbB3-null mice may result from decreased epithelial cell survival. We therefore measured basal- and DSS-induced apoptosis in the remaining intact crypts in ErbB2- and ErbB3-null mice during the injury and recovery period using TUNEL staining. In unchallenged mice, epithelial deletion of ErbB2 had no effect on the level of epithelial apoptosis (Figure 6a and c), whereas ErbB3 deletion increased basal epithelial apoptosis (Figure 6b and d) even without DSS injury. Following the 4-day DSS injury, all genotypes (ErbB2 $\mathrm{KO}^{\mathrm{IEC}}$, ErbB3 $\mathrm{KO}^{\mathrm{IEI}}$ and their respective control mice) showed an increased rate of apoptosis compared with water-treated mice. However, during this injury period, only ErbB3 expression had an effect on apoptosis with a significantly increased apoptotic rate in the
ErbB3-null epithelium compared with wild-type mice controls $(327 \%$ increase compared with wild-type controls; Figure $6 \mathrm{~b}$ and $\mathrm{d}$ ). This appears to be consistent with the more significant effect of ErbB3 deletion on short-term DSS injury compared with that of ErbB2 deletion (Figure 3 and Supplementary Figure 4). Interestingly, apoptotic rates were significantly increased by either ErbB2 or ErbB3 deletion during the recovery period (267 and 258\% increase compared with controls, respectively; Figure 6a-d). Again, these data are also consistent with the histopathological findings that ErbB2- and ErbB3-null mice had extensive injury, specifically during this recovery period (Figures 2 and 3). These data demonstrate that ErbB2 and ErbB3 protect against colitis through promoting epithelial cell survival, and that ErbB3 regulates epithelial apoptosis basally, during injury and during recovery, whereas ErbB2 is important only during recovery from injury.

\section{DISCUSSION}

In this study, using mice with intestinal epithelium-specific deletion of ErbB2 or ErbB3, we uncovered a direct reparative role for colon epithelial ErbB2 and ErbB3 following DSSinduced injury and a lesser role for ErbB3 in regulating the extent of the injury itself. We show that ErbB2 $\mathrm{KO}^{\mathrm{IEC}}$ and ErbB3 $\mathrm{KO}^{\mathrm{IEI}}$ mice had markedly reduced recovery following DSS-induced colitis, most likely due to increased epithelial cell apoptosis and increased TNF- $\alpha$ production. Interestingly, a single round of DSS treatment in ErbB3 $\mathrm{KO}^{\mathrm{IEC}}$ mice resulted in long-term histological alterations, with a failure to resolve inflammation and injury by 6 weeks following DSS administration. This study is the first to uncover the roles of ErbB2 and ErbB3 as important reparative factors following colonic injury.

Immediately following DSS administration, neither ErbB2 $\mathrm{KO}^{\mathrm{IEC}}$ nor ErbB3 $\mathrm{KO}^{\mathrm{IEI}}$ mice exhibited increased injury; however, both genotypes presented with a greater loss of body weight than controls (Figures 2 and 3). However, we did observe a small protective role for epithelial ErbB3 during this injury period, as ErbB3 $\mathrm{KO}^{\mathrm{IEC}}$ mice (constitutive deletion of ErbB3) had greater injury scores (Supplementary Figure 4), which confirms previous findings from Lee et al. ${ }^{17}$ Moreover, deletion of ErbB3 in ErbB3 $\mathrm{KO}^{\mathrm{IEI}}$ mice (inducible deletion of ErbB3 in adult mice) did result in increased epithelial cell apoptosis and decreased cell proliferation during DSS injury, despite there being no differences in injury scores. The reasons for this discrepancy between the two different lines of epithelial ErbB3 knockout may involve strain-specific differences or compensatory changes in other factors resulting from embryonic deletion of ErbB3 in ErbB3 $\mathrm{KO}^{\mathrm{IEC}}$ mice. Nevertheless, we conclude that epithelial ErbB3, but not epithelial ErbB2, has a small protective role from colonic injury during DSS administration, likely by promoting epithelial cell survival and the maintenance of cell proliferation.

Importantly, we found that epithelial ErbB2 and ErbB3 are important reparative factors during recovery from injury. For 
these studies, we made a distinction between short-term (ie, 3 days) and long-term (ie, 6 weeks) recovery periods following a single round of DSS administration. Epithelial ErbB2 was required for normal short-term recovery from colitis, and ErbB2 $\mathrm{KO}^{\mathrm{IEC}}$ mice showed elevated injury scores, cytokine expression, hyperproliferation and epithelial apoptosis during this period. However, the effect of epithelial ErbB2 knockout was confined to the acute period; following 6 weeks of recovery, we found no histological differences between wild-type and ErbB2 $\mathrm{KO}^{\mathrm{IEC}}$ mice. Thus, epithelial ErbB2 appears to be important for optimal early recovery of the epithelium from injury, but may be dispensable for long-term regeneration. However, it is important to note that the model used in this study involved only a single inflammatory insult; upon repeated injury or chronic injury, such as that which occurs in inflammatory bowel disease patients, the role of ErbB2 in ongoing epithelial repair could be more important.

Although epithelial ErbB3 appeared to have a small protective role in determining the extent of injury during DSS administration, we found that it was required for optimal regeneration both in the short term (3 days) and in the long term (6 weeks). Mice with inducible ErbB3 deletion (ErbB3 $\mathrm{KO}^{\mathrm{IEI}}$ ) had increased colonic injury, TNF- $\alpha$ expression, hyperproliferation and epithelial apoptosis during short-term recovery from DSS. Moreover, the extent of this injury was much greater than wild-type controls and involved much of the colon with areas of complete epithelial ulceration. Although epithelial ErbB2 knockouts showed a similar phenotype during this period, loss of ErbB2 increased TNF- $\alpha$ and IFN- $\gamma$ transcripts; in contrast, ErbB3 deletion only affected TNF- $\alpha$ expression. Interestingly, in the long-term recovery period, we found that expression of epithelial ErbB3 in the tamoxifen-inducible strain $\left(\mathrm{ErbB} 3 \mathrm{KO}^{\mathrm{IEI}}\right)$ was restored, which, we conclude, contributed to the observed normal regeneration in these mice (Supplementary Figure 5). Indeed, this type of strong selective pressure for the restoration of wild-type intestinal epithelial cells following inducible deletion has been reported by others. ${ }^{32}$ In contrast, the permanent and constitutive deletion of epithelial ErbB3 (ErbB3 $\mathrm{KO}^{\mathrm{IEC}}$ ) produced substantial long-term changes in epithelial recovery, with injury and inflammation that persisted throughout this 6-week period. These differences emphasize the importance of ErbB3 in long-term regeneration, as it appeared that a strong selective pressure was involved in the reestablishment of ErbB3 expression in the inducible strain.

ErbB2 and ErbB3 are implicated in cell proliferation, particularly in breast tumor cells. ${ }^{13}$ During recovery from
DSS colitis, epithelial cells undergo extensive hyperproliferation to regenerate damaged crypts and repopulate the denuded epithelium. ${ }^{23}$ Although we observed a significant decrease in proliferation in ErbB3 $\mathrm{KO}^{\mathrm{IEI}}$ mice relative to wildtype controls after 4 days of DSS administration, this decrease may be related to the greater degree of crypt damage and/or a greater degree of epithelial apoptosis in these mice during injury (Figure 6), indirectly leading to a decrease in epithelial progenitors during this injury phase. For instance, it has been reported that DSS preferentially affects stem cells and progenitor cells in the base of the crypt; ${ }^{28}$ thus, this reduction in proliferation may be due to increased apoptosis of progenitor cells caused by DSS in an ErbB3-null epithelium.

Elevated apoptosis is important in the etiology of colon disorders and is seen in both ulcerative colitis patients and in the mouse DSS colitis model. ${ }^{23,28,33}$ Indeed, epithelial apoptosis appears to be one of the mechanisms through which DSS induces colitis. Increased apoptosis leads to a disruption of the intestinal barrier and increased exposure of lamina propria immune cells to luminal antigens; in turn, subsequent colonic inflammation further increases epithelial injury. ${ }^{34-36}$ Apoptotic rates were comparable between ErbB2 $\mathrm{KO}^{\mathrm{IEC}}$ and wild-type mice in the unchallenged state and following DSS injury. However, during epithelial recovery, ErbB2 $\mathrm{KO}^{\mathrm{IEC}}$ mice had higher apoptotic rates than those of littermate controls. In addition, there was a dramatic reduction in the number of surviving crypts that could support proliferation in the recovery phase in ErbB2 $\mathrm{KO}^{\mathrm{IEC}}$ and ErbB3 $\mathrm{KO}^{\mathrm{IEI}}$ mice compared with their wild-type controls. Thus, during this early recovery period, increased cell death in epithelial cells leads to more severe colitis and early recovery failure in ErbB2 $\mathrm{KO}^{\mathrm{IEC}}$ mice. Our previous report demonstrated that transactivation of ErbB2 by TNF- $\alpha$ is required for colonic epithelial survival following exposure to TNF- $\alpha .{ }^{10}$ Indeed, TNF- $\alpha$ levels are elevated in both DSSinduced colitis and in inflammatory bowel disease patients; furthermore, anti-TNF- $\alpha$ antibodies reduce colitis progression. ${ }^{37}$ In our study, we confirmed that TNF- $\alpha$ transcripts were increased in recovering ErbB2 and ErbB3 knockout mice. Thus, one potential mechanism for the delayed shortterm recovery following DSS withdrawal in ErbB2 $\mathrm{KO}^{\mathrm{IEC}}$ mice is due to increased TNF- $\alpha$-induced apoptosis in the absence of ErbB2 transactivation.

Surprisingly, inducible deletion of ErbB3 resulted in increased epithelial cell death in unchallenged mice. In a recent study, Lee et al $^{17}$ showed that constitutive deletion of ErbB3 in the colon epithelium did not alter basal intestinal epithelial cell survival. Our studies involved inducible

Figure 5 Loss of ErbB2 or ErbB3 exacerbates epithelial hyperproliferative response during recovery from dextran sulfate sodium (DSS)-induced colitis. $(\mathbf{a}, \mathbf{b})$ Immunostaining for the proliferative marker Ki67 (brown nuclei) in colonic sections of ErbB2 $\mathrm{KO}^{\mathrm{IEC}}(\mathbf{a})$, and ErbB3 $\mathrm{KO}^{\mathrm{IEI}}$ mice (b), and their respective wild-type controls treated with water, DSS for 4 days or DSS followed by a 3-day recovery period, as indicated. Images are representative of 8-12 mice per group. Scale bars, $100 \mu \mathrm{m}$. (c, d) The number of Ki67-positive cells per crypt were quantified in a blinded manner. Bars indicate mean values. 
a
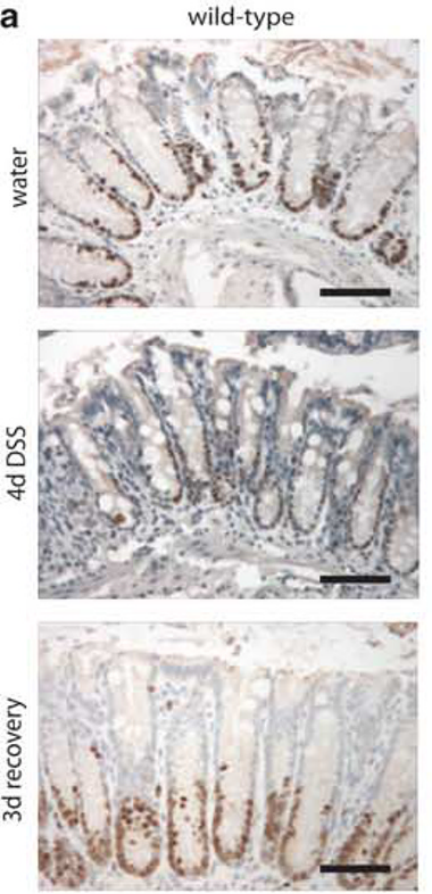

ErbB2 KOIEC
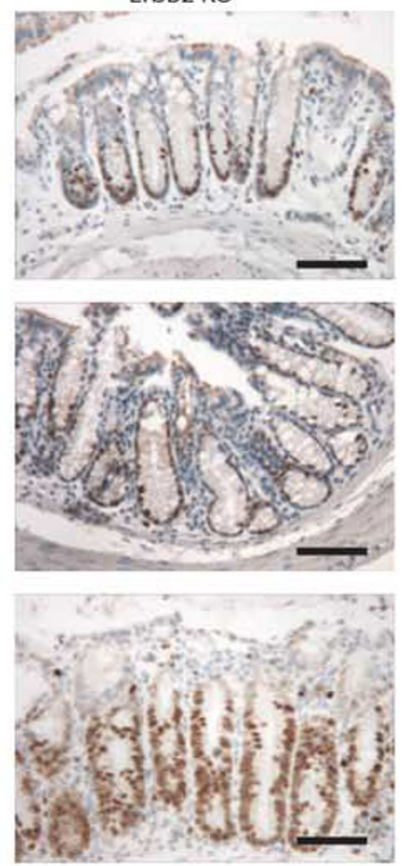

C b
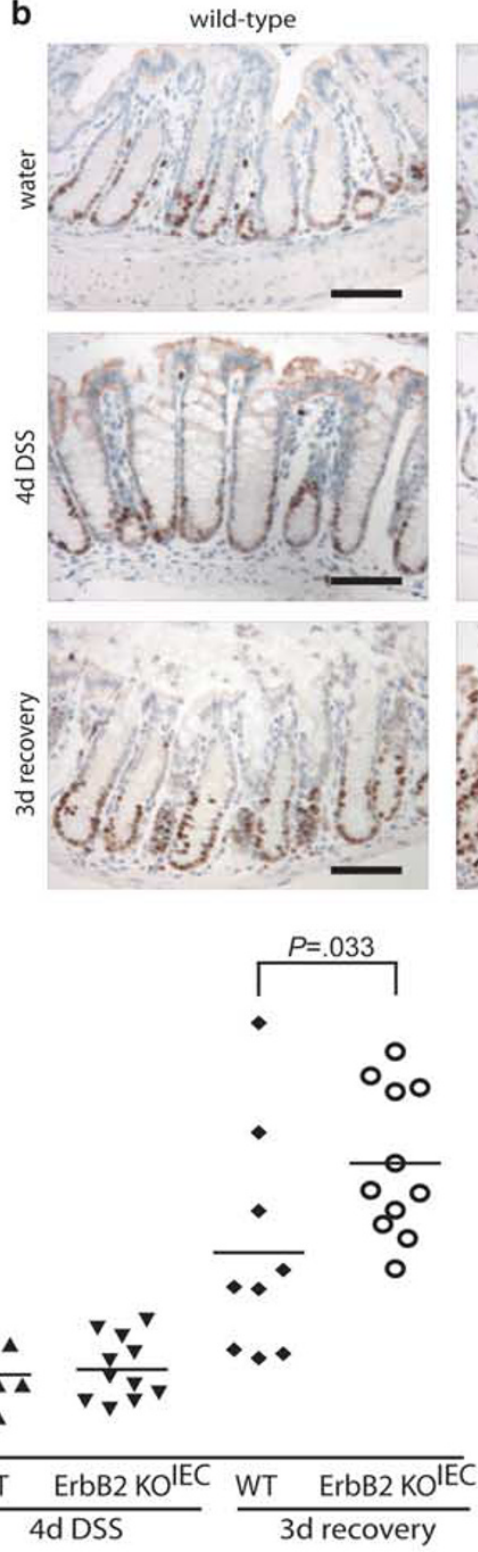

d

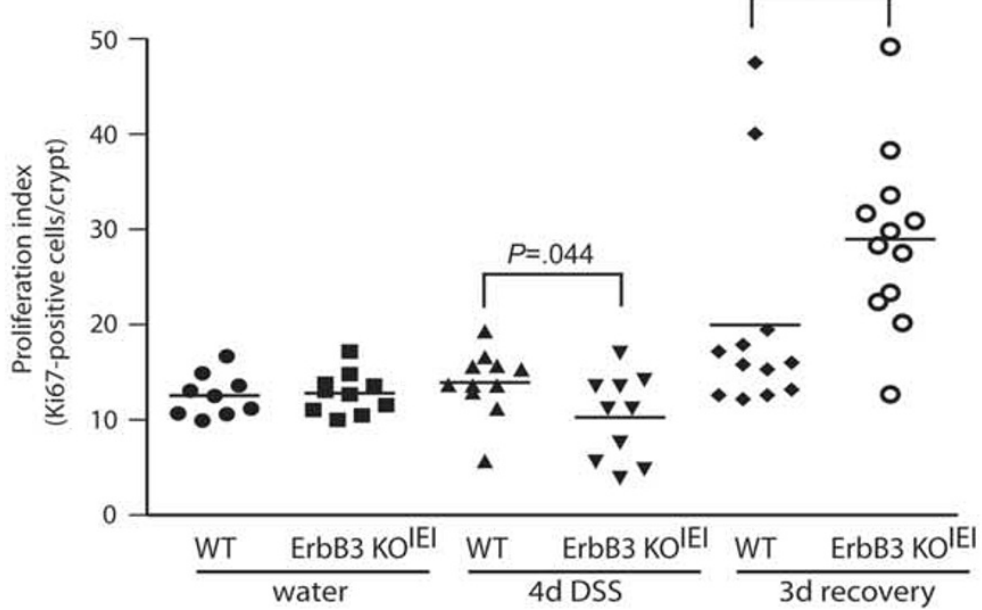


a
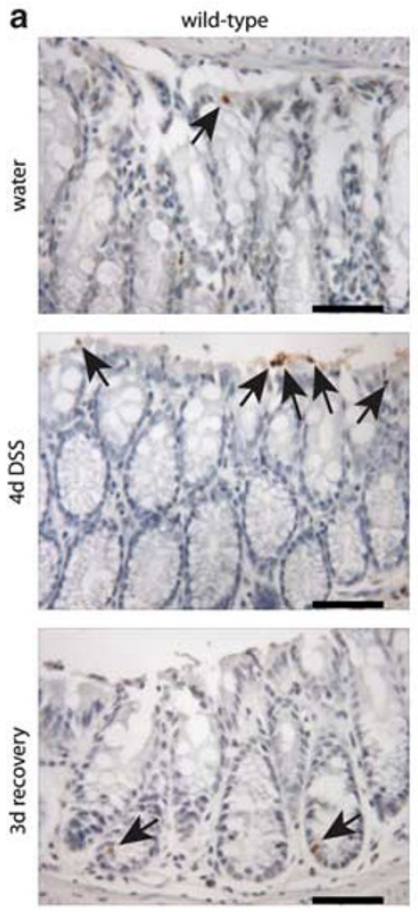

ErbB2 KO IEC
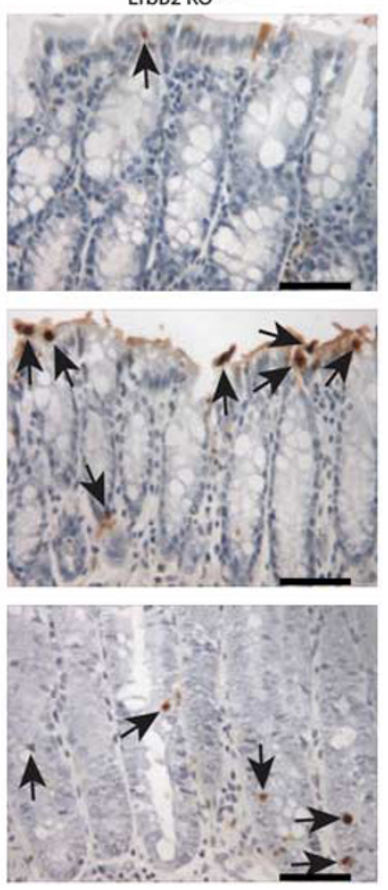

C b
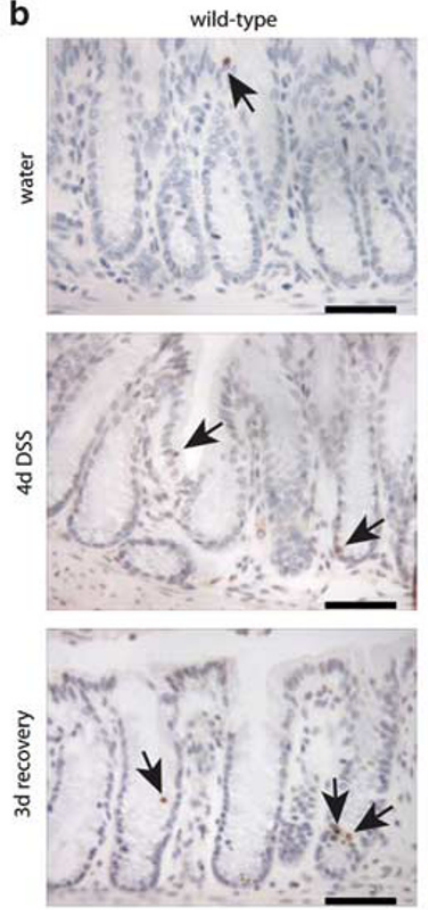

$\begin{array}{r}P=.72 \\ \hline\end{array}$

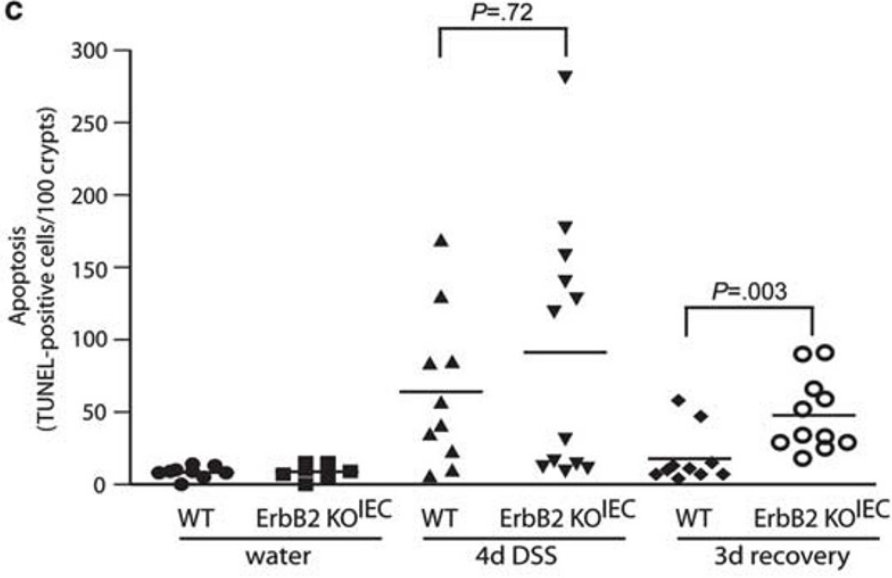

d

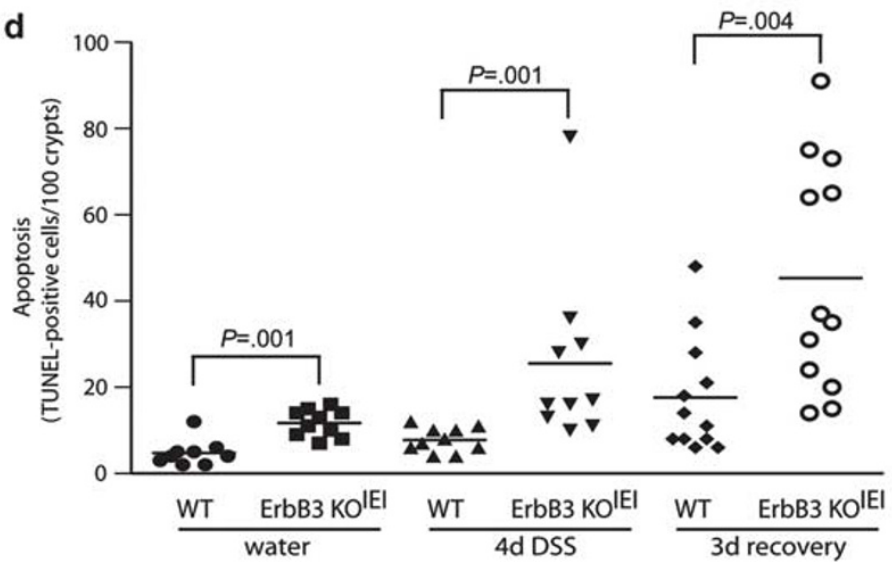

Figure 6 Loss of ErbB2 or ErbB3 increases colonic epithelial apoptosis. (a, b) Apoptotic cells (arrows) in colon sections were detected by terminal deoxynucleotidyl transferase-mediated dNTP nick-end labeling (TUNEL) staining from wild-type or knock-out mice treated with water, dextran sulfate sodium (DSS) for 4 days or DSS followed by a 3-day recovery period, as indicated. Images are representative of $8-12$ mice per group. Scale bars, $50 \mu$ m. (c, d) The number TUNEL-positive cells per 100 crypts were quantified in a blinded manner. Bars indicate mean values. 
deletion of ErbB3 in adult mice with a mature gastrointestinal system. In contrast, constitutive villin-Cre constructs used in their study delete ErbB3 starting from embryonic day $9 .^{24}$ One possibility for this discrepancy is that early embryonic deletion of ErbB3 may lead to developmental compensation by other ErbB family members, which may explain the differences in our respective studies.

Although loss of ErbB3 increased injury during DSS administration, the protective role of epithelial ErbB3 was even more apparent during recovery, in which ErbB3 $\mathrm{KO}^{\mathrm{IEI}}$ colons displayed greatly exaggerated injury and apoptosis. Furthermore, these changes failed to resolve in $\mathrm{ErbB} 3 \mathrm{KO}^{\mathrm{IEC}}$ mice over a 6-week period. These data suggest that the ErbB3-deleted intestinal epithelium shows different patterns of DSS-induced toxicity than that with ErbB2 deletion. Although these studies were performed in mice with different genetic backgrounds, when compared with their respective wild-type controls, epithelial ErbB3 appeared to have a greater role in regulating levels of apoptosis basally, and during injury and short- and long-term recovery. A mechanistic reason may be that ErbB3 is a potent activator of PI3 kinase, as it possesses multiple PI3 kinase-binding sites; as this is known to be an important regulator of cell survival, ${ }^{5,14}$ this may explain why ErbB3 is more potent than ErbB2 to prevent apoptosis. Another mechanism through which ErbB3 deletion resulted in severe crypt damage and inflammation might be that the ErbB3-deleted intestinal epithelium is more sensitive to TNF- $\alpha$-induced toxicity compared with that containing wild-type ErbB3. Our group has shown that TNF- $\alpha$ can activate EGFR, ErbB2, as well as ErbB4 to promote epithelial cell survival, and knockdown of any of these ErbBs significantly potentiates TNF- $\alpha$-induced apoptosis. ${ }^{10,38}$ Activation of ErbB3 depends on heterodimerization with other ErbBs; thus, it is also possible that increased TNF- $\alpha$-induced transactivation may also promote ErbB3regulated signaling pathways. Indeed, the ErbB2-ErbB3 heterodimer is the most potent signaling pair amongst the ErbB heterodimers, ${ }^{5}$ and ErbB3 is the favored heterodimerization partner for ErbB2. ${ }^{39}$ Cell death following the loss of ErbB3 may therefore represent a higher sensitivity of the epithelium to TNF- $\alpha$-induced apoptosis. Therefore, our data suggest that ErbB2 and ErbB3 each contribute complementary yet non-redundant roles in regulating intestinal injury and repair.

In summary, the results of our study demonstrate that ErbB2 and ErbB3 are important regulators of colonic epithelial cell responses having a critical role in optimizing intestinal recovery from injury. These findings expand the known range of activities of EGFR family receptor tyrosine kinases, suggesting that strategies designed to activate ErbB2 and ErbB3 may be of therapeutic value in promoting recovery following colon injury.

Supplementary Information accompanies the paper on the Laboratory Investigation website (http://www.laboratoryinvestigation.org)

\section{ACKNOWLEDGEMENTS}

We would like to thank William Muller for providing the ErbB2-floxed mice, David Threadgill for providing the ErbB3-floxed mice, Sylvie Robine for providing the villin-Cre and villin-Cre ERT2 mice, and Frank Revetta for providing technical assistance in immunohistochemical staining. This study was supported by NIH Grant R01DK056008 (to DBP), a Research Fellowship Award from the Crohn's and Colitis Foundation of America (to YQZ), a Fellowship from the Canadian Institutes of Health Research (to PED), and the Vanderbilt Digestive Diseases Research Center (VDDRC; NIH Award P30DK058404), including the VDDRC Histology core laboratory.

\section{DISCLOSURE/CONFLICT OF INTEREST}

The authors declare no conflict of interest.

1. Carpenter G CS. EGF: receptor interactions and the stimulation of cell growth. In: Lefkowitz R (ed). Receptors and recognition, Series B, Volume 13, Chapman and Hall: London, 1981, pp 43-66.

2. Polk DB. Epidermal growth factor receptor-stimulated intestinal epithelial cell migration requires phospholipase C activity. Gastroenterology 1998;114:493-502.

3. Procaccino $F$, Reinshagen $M$, Hoffmann $P$, et al. Protective effect of epidermal growth factor in an experimental model of colitis in rats. Gastroenterology 1994;107:12-17.

4. Sinha A, Nightingale J, West KP, et al. Epidermal growth factor enemas with oral mesalamine for mild-to-moderate left-sided ulcerative colitis or proctitis. N Engl J Med 2003;349:350-357.

5. Baselga J, Swain SM. Novel anticancer targets: revisiting ERBB2 and discovering ERBB3. Nat Rev Cancer 2009;9:463-475.

6. Lee $\mathrm{KF}$, Simon $\mathrm{H}$, Chen $\mathrm{H}$, et al. Requirement for neuregulin receptor erbB2 in neural and cardiac development. Nature 1995;378:394-398.

7. Jackson-Fisher AJ, Bellinger $G$, Ramabhadran $R$, et al. ErbB2 is required for ductal morphogenesis of the mammary gland. Proc Natl Acad Sci USA 2004;101:17138-17143.

8. Andrechek ER, Hardy WR, Girgis-Gabardo AA, et al. ErbB2 is required for muscle spindle and myoblast cell survival. Mol Cell Biol 2002;22:4714-4722.

9. Lucs AV, Muller WJ, Muthuswamy SK. Shc is required for ErbB2-induced inhibition of apoptosis but is dispensable for cell proliferation and disruption of cell polarity. Oncogene 2010;29:174-187.

10. Yamaoka T, Yan F, Cao H, et al. Transactivation of EGF receptor and ErbB2 protects intestinal epithelial cells from TNF-induced apoptosis. Proc Natl Acad Sci USA 2008;105:11772-11777.

11. Travis A, Pinder SE, Robertson JF, et al. C-erbB-3 in human breast carcinoma: expression and relation to prognosis and established prognostic indicators. Br J Cancer 1996;74:229-233.

12. Bobrow $L G$, Millis RR, Happerfield LC, et al. c-erbB-3 protein expression in ductal carcinoma in situ of the breast. Eur J Cancer 1997;33:1846-1850.

13. Holbro T, Beerli RR, Maurer F, et al. The ErbB2/ErbB3 heterodimer functions as an oncogenic unit: ErbB2 requires ErbB3 to drive breast tumor cell proliferation. Proc Natl Acad Sci USA 2003;100:8933-8938.

14. Soltoff SP, Carraway III KL, Prigent SA, et al. ErbB3 is involved in activation of phosphatidylinositol 3-kinase by epidermal growth factor. Mol Cell Biol 1994;14:3550-3558.

15. Sithanandam G, Fornwald LW, Fields J, et al. Inactivation of ErbB3 by siRNA promotes apoptosis and attenuates growth and invasiveness of human lung adenocarcinoma cell line A549. Oncogene 2005;24: 1847-1859.

16. Erickson $\mathrm{SL}$, O'Shea $\mathrm{KS}$, Ghaboosi $\mathrm{N}$, et al. ErbB3 is required for normal cerebellar and cardiac development: a comparison with ErbB2-and heregulin-deficient mice. Development 1997;124:4999-5011.

17. Lee $\mathrm{D}, \mathrm{Yu} \mathrm{M}$, Lee $\mathrm{E}$, et al. Tumor-specific apoptosis caused by deletion of the ERBB3 pseudo-kinase in mouse intestinal epithelium. J Clin Invest 2009;119:2702-2713.

18. Egger B, Procaccino F, Lakshmanan J, et al. Mice lacking transforming growth factor alpha have an increased susceptibility to dextran sulfate-induced colitis. Gastroenterology 1997;113:825-832.

19. Egger B, Buchler MW, Lakshmanan J, et al. Mice harboring a defective epidermal growth factor receptor (waved-2) have an increased susceptibility to acute dextran sulfate-induced colitis. Scand J Gastroenterol 2000;35:1181-1187. 
20. Lee $D$, Pearsall RS, Das $S$, et al. Epiregulin is not essential for development of intestinal tumors but is required for protection from intestinal damage. Mol Cell Biol 2004;24:8907-8916.

21. Okayasu I, Hatakeyama S, Yamada M, et al. A novel method in the induction of reliable experimental acute and chronic ulcerative colitis in mice. Gastroenterology 1990;98:694-702.

22. Cooper HS, Murthy SN, Shah RS, et al. Clinicopathologic study of dextran sulfate sodium experimental murine colitis. Lab Invest 1993;69:238-249.

23. Fukata $M$, Chen A, Klepper A, et al. Cox-2 is regulated by Toll-like receptor-4 (TLR4) signaling: Role in proliferation and apoptosis in the intestine. Gastroenterology 2006;131:862-877.

24. el Marjou F, Janssen KP, Chang BH, et al. Tissue-specific and inducible Cre-mediated recombination in the gut epithelium. Genesis 2004; 39:186-193.

25. Edelblum $\mathrm{KL}$, Washington $\mathrm{MK}$, Koyama $\mathrm{T}$, et al. Raf protects against colitis by promoting mouse colon epithelial cell survival through NFkappaB. Gastroenterology 2008;135:539-551.

26. Whitehead $\mathrm{RH}$, VanEeden $\mathrm{PE}$, Noble MD, et al. Establishment of conditionally immortalized epithelial cell lines from both colon and small intestine of adult $\mathrm{H}-2 \mathrm{~Kb}$-tsA58 transgenic mice. Proc Natl Acad Sci USA 1993;90:587-591.

27. Dieleman LA, Palmen MJ, Akol H, et al. Chronic experimental colitis induced by dextran sulphate sodium (DSS) is characterized by Th1 and Th2 cytokines. Clin Exp Immunol 1998;114:385-391.

28. Martinez JA, Williams CS, Amann JM, et al. Deletion of Mtgr1 sensitizes the colonic epithelium to dextran sodium sulfate-induced colitis. Gastroenterology 2006;131:579-588.

29. Yan F, John SK, Wilson G, et al. Kinase suppressor of Ras-1 protects intestinal epithelium from cytokine-mediated apoptosis during inflammation. J Clin Invest 2004;114:1272-1280.
30. Cario E, Gerken G, Podolsky DK. Toll-like receptor 2 controls mucosal inflammation by regulating epithelial barrier function. Gastroenterology 2007;132:1359-1374.

31. Froicu M, Zhu $Y$, Cantorna MT. Vitamin D receptor is required to control gastrointestinal immunity in IL-10 knockout mice. Immunology 2006;117:310-318.

32. Sato $\mathrm{T}$, van Es $\mathrm{JH}$, Snippert $\mathrm{HJ}$, et al. Paneth cells constitute the niche for Lgr5 stem cells in intestinal crypts. Nature 2011;469: 415-418.

33. Iwamoto M, Koji T, Makiyama K, et al. Apoptosis of crypt epithelial cells in ulcerative colitis. J Pathol 1996;180:152-159.

34. Vetuschi A, Latella $G$, Sferra $R$, et al. Increased proliferation and apoptosis of colonic epithelial cells in dextran sulfate sodium-induced colitis in rats. Dig Dis Sci 2002;47:1447-1457.

35. Satoh $Y$, Ishiguro $Y$, Sakuraba $H$, et al. Cyclosporine regulates intestinal epithelial apoptosis via TGF-beta-related signaling. Am J Physiol Gastrointest Liver Physiol 2009;297:G514-G519.

36. Lorenz RG, McCracken VJ, Elson CO. Animal models of intestina inflammation: ineffective communication between coalition members. Springer Semin Immunopathol 2005;27:233-247.

37. Siegmund B, Fantuzzi G, Rieder F, et al. Neutralization of interleukin-18 reduces severity in murine colitis and intestinal IFN-gamma and TNF-alpha production. Am J Physiol Regul Integr Comp Physiol 2001; 281:R1264-R1273.

38. Frey MR, Edelblum KL, Mullane MT, et al. The ErbB4 growth factor receptor is required for colon epithelial cell survival in the presence of TNF. Gastroenterology 2009;136:217-226.

39. Tzahar E, Waterman H, Chen $\mathrm{X}$, et al. A hierarchical network of interreceptor interactions determines signal transduction by $\mathrm{Neu}$ differentiation factor/neuregulin and epidermal growth factor. Mol Cell Biol 1996;16:5276-5287. 